\title{
Fenofibric acid prevents retinal pigment epithelium disruption induced by interleukin- $\beta$ by suppressing AMP-activated protein kinase (AMPK) activation
}

\author{
M. Villarroel • M. Garcia-Ramírez • L. Corraliza • \\ C. Hernández • R. Simó
}

Received: 3 November 2010 / Accepted: 18 January 2011 /Published online: 3 March 2011

(C) Springer-Verlag 2011

\begin{abstract}
Aims/hypothesis The mechanisms involved in the beneficial effects of fenofibrate on the development and progression of diabetic macular oedema (DMO) remain to be elucidated. To shed light on this issue we have explored the effect of fenofibric acid on the barrier function of human retinal pigment epithelium (RPE) cells.

Methods ARPE-19 cells (a human RPE line) were cultured for 18 days under standard conditions and under conditions leading to the disruption of the monolayer (D-glucose, $25 \mathrm{mmol} / 1$, with IL- $1 \beta, 10 \mathrm{ng} / \mathrm{ml}$, added at days 16 and 17). Fenofibric acid, $25 \mu \mathrm{mol} / 1$ and $100 \mu \mathrm{mol} / \mathrm{l}$, was added on the last 3 days of the experiment (one application/day). RPE cell permeability was evaluated by measuring apical-
\end{abstract}

Electronic supplementary material The online version of this article (doi:10.1007/s00125-011-2089-5) contains supplementary material, which is available to authorised users.

M. Villarroel · M. Garcia-Ramírez · L. Corraliza • C. Hernández · R. Simó $(\bowtie)$

Centro de Investigación Biomédica en Red de Diabetes y

Enfermedades Metabólicas Asociadas (CIBERDEM), Spain

e-mail: rsimo@ir.vhebron.net

URL: www.ciberdem.org

M. Villarroel • M. Garcia-Ramírez $\cdot$ L. Corraliza • C. Hernández R. Simó

Diabetes and Metabolism Research Unit,

Vall d'Hebron Institut de Recerca (VHIR),

Pg Vall d'Hebron 119-129,

08035 Barcelona, Spain

M. Villarroel • M. Garcia-Ramírez • L. Corraliza • C. Hernández •

R. Simó

Universitat Autònoma de Barcelona,

Barcelona, Spain basolateral movements of FITC-dextran (40 kDa). The production of tight junction proteins and AMP-activated protein kinase (AMPK) phosphorylation was assessed by western blot. Immunohistochemical studies of tight junction proteins and small interfering RNA transfection to AMPK were also performed in ARPE-19 monolayers.

Results Treatment of ARPE-19 cells with fenofibric acid significantly reduced the increment of permeability and the breakdown of the ARPE-19 cell monolayer induced by Dglucose, $25 \mathrm{mmol} / \mathrm{l}$, and IL-1 $\beta, 10 \mathrm{ng} / \mathrm{ml}$, in a dose-dependent manner. This effect was unrelated to changes in the content of tight junction proteins. Fenofibric acid prevented the activation of AMPK induced by IL-1 $\beta$ and the hyperpermeability induced by IL-1 $\beta$ was blocked by silencing AMPK.

Conclusions/interpretation Disruption of RPE induced by IL-1 $\beta$ is prevented by fenofibric acid through its ability to suppress AMPK activation. This mechanism could be involved in the beneficial effects of fenofibrate on DMO development.

Keywords AMPK - Blood-retinal barrier - Diabetic macular oedema $\cdot$ Diabetic retinopathy Fenofibric acid . IL-1 $\beta \cdot$ Permeability $\cdot$ Retinal pigment epithelium
Abbreviations
AICAR 5-Aminoimidazole-4-carboxamide riboside
AMPK AMP-activated protein kinase
BRB Blood-retinal barrier
DAPI 4'-6-Diamidino-2-phenylindole
DMO Diabetic macular oedema
DMSO Dimethylsulphoxide
DR Diabetic retinopathy
LDH Lactate dehydrogenase
NPDR Non-proliferative diabetic retinopathy
PDR Proliferative diabetic retinopathy
PPAR Peroxisome proliferator-activated receptor 
RPE Retinal pigment epithelium

ZO-1 Zonula occludens-1

\section{Introduction}

Proliferative diabetic retinopathy (PDR) remains the leading cause of blindness and vision loss in adults under 40 years in the developed world [1]. Diabetic macular oedema (DMO), another important event that occurs in diabetic retinopathy (DR), is more frequent in type 2 than in type 1 diabetes, and it is the primary cause of poor visual acuity in type 2 diabetes. Because of the high prevalence of type 2 diabetes, DMO is the main cause of visual impairment for diabetic patients [2]. Vascular leakage caused by the breakdown of the blood-retinal barrier (BRB) is the main event involved in the pathogenesis of DMO [3, 4]. In the Fenofibrate Intervention and Event Lowering in Diabetes (FIELD) study on DR, treatment with fenofibrate (a peroxisome proliferatoractivated receptor [PPAR]- $\alpha$ agonist) reduced the need for laser treatment for DMO and PDR by 30\% [5]. In addition, the Action to Control Cardiovascular Risk in Diabetes (ACCORD) Eye Study has recently shown 40\% reduction in the odds of having progression of DR in the group of patients receiving fenofibrate plus simvastatin compared with those patients treated with placebo plus simvastatin [6]. However, the mechanisms by which fenofibrate exert its beneficial effects in DR remain to be elucidated [7, 8]. Because of the notable effect of fenofibrate in preventing DMO progression, it could be hypothesised that fenofibrate exerts an important effect in preventing and/or restoring the sealing function of the BRB. In fact, it has been recently reported that PPAR- $\alpha$ WY 14643 reduces inflammation and vascular leakage in a murine model of lung injury [9].

The BRB is composed of two elements: (1) the inner $\mathrm{BRB}$, which is constituted by the blood vessels of the retina and directly controls the flux into the inner retina; and (2) the outer BRB formed by the retinal pigment epithelium (RPE), which controls the flow of solutes and fluid from the choroidal vasculature into the outer retina $[10,11]$. The strict control of fluid and solutes that cross the inner and the outer BRB is achieved through well-developed tight junctions, zonula occludens-1 (ZO-1), claudins and occludin being the most studied of these proteins. While extensive work has been carried out to identify the factors involved in the disruption of the tight junctions of the inner $\mathrm{BRB}$, the mechanisms implicated in the regulation of the outer BRB have been poorly explored.

The increase in pro-inflammatory cytokines plays a key role in the pathogenesis of DMO $[4,12,13]$. In fact, treatment of RPE cells with either serum, interferon- $\gamma$, tumour necrosis factor- $\alpha$, hepatocyte growth factor (HGF), IL-1 $\beta$ or placental growth factor-1 (PLGF-1) increases permeability and alters the levels or content of tight junction molecules [14-18]. As IL- $1 \beta$ plays an essential role in the development of DR [1922], we decided to use this cytokine to provoke the breakdown of the RPE cell monolayer and to test the potential preventive effects of fenofibrate.

On these bases, the aim of the present study was to explore the effect of fenofibric acid (the active metabolite of fenofibrate) on the barrier function and the levels of tight junction proteins (occludin, ZO-1 and claudin-1) in a human RPE cell line cultured under different glucose concentrations with and without IL-1 $\beta$. In addition, the role of AMPactivated protein kinase (AMPK; a cellular energy sensor) in mediating the hyperpermeability induced by IL- $1 \beta$ and the effect of fenofibrate on AMPK activation was also evaluated.

\section{Methods}

Human RPE cell cultures ARPE-19, a spontaneously immortalised human RPE cell line, was obtained from American Type Culture Collection (Manassas, VA, USA). Cells were cultured in euglycaemic conditions (D-glucose, $5.5 \mathrm{mmol} / \mathrm{l}$ ) and hyperglycaemic conditions (D-glucose, $25 \mathrm{mmol} / \mathrm{l}$ ) for 18 days at $37^{\circ} \mathrm{C}$ under $5 \%$ (vol./vol.) $\mathrm{CO}_{2}$ in medium (DMEM/F12) supplemented with 10\% (vol./vol.) FBS (Hyclone; Thermo Fisher Scientific, UT, USA) and $1 \%$ (vol./vol.) penicillin/streptomycin (Hyclone; Thermo Fisher Scientific). ARPE-19 cells from passage 20 were used and the medium was changed every 3-4 days. For permeability studies, ARPE-19 cells were seeded at 400,000 cells $/ \mathrm{ml}(80,000 \mathrm{RPE}$ cells/well $)$ in $0.33 \mathrm{~cm}^{2}$ HTS-Transwells (Costar; Corning, NY, USA). For real-time PCR, western blot analysis and immunofluorescence cells were seeded at 20,000 cells $/ \mathrm{ml}$.

Four different conditions were tested in cells cultured under either 5 or $25 \mathrm{mmol} / \mathrm{l}$ D-glucose: (1) control cells that did not receive any treatment - in order to rule out a potential bias by an osmotic effect in cells cultured under D-glucose, $25 \mathrm{mmol} / \mathrm{l}$, permeability was also measured using mannitol (D-glucose, $5.5 \mathrm{mmol} / \mathrm{l}$, and mannitol, $19.5 \mathrm{mmol} / \mathrm{l}$ ) as an osmotic control agent; (2) cells treated with IL-1 $\beta$ (Preprotech; Rock Hill, NJ, USA), $10 \mathrm{ng} / \mathrm{ml}$, for $48 \mathrm{~h}$ (days 16 and 17 at one application/day) in order to provoke the disruption of the monolayer; (3) cells treated with two concentrations of fenofibric acid, $25 \mu \mathrm{mol} / 1$ and $100 \mu \mathrm{mol} / 1$, for $72 \mathrm{~h}$ (days 15 , 16 and 17 at one application/day) to evaluate the potential cytotoxic effects of fenofibric acid; (4) cells treated with two concentrations of fenofibric acid, 25 and $100 \mu \mathrm{mol} / 1$, for $72 \mathrm{~h}$ (days 15, 16 and 17 at one application/day) and with IL-1 $\beta$, $10 \mathrm{ng} / \mathrm{ml}$, for $48 \mathrm{~h}$ (days 16 and 17 at one application/day) in order to evaluate the effect of fenofibric acid in preventing the cell damage provoked by IL-1 $\beta$. 
In addition, some cells were treated with 5-aminoimidazole4-carboxamide riboside (AICAR; Santa Cruz Biotechnology; Santa Cruz, CA, USA), 2 mmol/1, for $48 \mathrm{~h}$ (days 16 and 17 at one application/day) to induce AMPK activation.

The cells were subjected to serum starvation (1\% [vol./vol.] FBS) during the treatments. Fenofibric acid was dissolved in dimethylsulphoxide (DMSO) but the final concentration of DMSO in the medium did not exceed $0.03 \%$ (vol./vol.). DMSO was added to the control culture medium at the same concentration.

Small interfering RNA transfection A small interfering RNA (siRNA) probe targeted to $A M P K \alpha 1$ (also known as $P R K A A 1$ ) and $A M P K \alpha 2$ (also known as PRKAA2) was purchased from Dharmacon (Lafayette, CO, USA). The target sequences for the human-specific PRKAAl Accell SMARTpool siRNA mixture are detailed in the electronic supplementary material (ESM). A control Accell siRNA pool of cyclophilin B (CYPB [also known as PPIB]; D001970-01) was used in the experiments. ARPE-19 cells were transfected with $1 \mu \mathrm{mol} / 1$ of Accell siRNAs in Accell delivery media (B-005000) according to the manufacturer's instructions. Cell monolayers were treated with Accell siRNA probes for $72 \mathrm{~h}$ and then the medium was replaced by standard conditions and the cells were treated with IL-1 $\beta(10 \mathrm{ng} / \mathrm{ml})$ and fenofibric acid $(100 \mu \mathrm{mol} / \mathrm{l})$ as described above.

Permeability assay The permeability of RPE cells was determined at 18 days by measuring the apical-tobasolateral movements of FITC-dextran (40 kDa) (Sigma, St Louis, MI, USA) following a procedure previously reported by this group [23].

Real-time PCR RNA was extracted with the RNeasy Micro kit (Qiagen Sciences, Germantown, MD, USA). RT-PCR specific primers were used (Thermo Scientific Solaris qPCR Gene Expression Assays; Thermo Fisher Scientific): PRKAA1 (AX-005027-00-0100) and PRKAA2 (AX005361-00-0100). Thermo Scientific Solaris qPCR Gene Expression ROX Master Mix was used. Automatic relative quantification data was obtained with ABI Prism 7000 SDS software (Applied Biosystems, Foster City, CA, USA) using RPS18 as endogenous control gene (AX-011890-00$0100)$. The $\Delta \Delta C_{\mathrm{t}}$ method was applied to estimate relative transcript levels. Levels of $18 \mathrm{~S}$ amplification were used for endogenous reference to normalise each sample threshold cycle value. Units are expressed as relative quantification.

Western blot analysis After treatment, cells were washed with ice-cold PBS and lysed with $200 \mu \mathrm{l}$ of lysis buffer (RIPA buffer: PMSF, $1 \mathrm{mmol} / 1 ; \mathrm{Na}_{3} \mathrm{VO}_{4}, 2 \mathrm{mmol} / \mathrm{l}$; NaF, $100 \mathrm{mmol} / \mathrm{l}$; and containing $1 \times$ protease inhibitor cocktail [Sigma]). Protein was extracted and a total of $20 \mu \mathrm{g}$ protein was resolved by $10 \%$ (vol./vol.) SDS-PAGE (for claudin-1 and occludin) and 7.5\% (vol./vol.) SDS-PAGE (for ZO-1, p-AMPK- $\alpha$-Thr ${ }^{172}$, AMPK) and transferred to a nitrocellulose membrane (GE Healthcare, Waukesha, WI, USA). The blots were probed with rabbit anti-claudin-1, rabbit anti-occludin and mouse anti-ZO-1, all diluted 1:1000, (Zymed Lab Gibco; Invitrogen, San Diego, CA, USA) and with rabbit anti-pAMPK- $\alpha$-Thr172 $(1: 1,000)$ and rabbit anti-AMPK $(1: 1,000$; Cell Signaling Technology, Danvers, MA, USA). After washing, goat anti-rabbit or -mouse horseradish peroxidase (HRP)-conjugated secondary antibody (Pierce; Thermo Scientific, Rockford, IL, USA) was applied and proteins were visualised using the chemiluminescent HRP substrate Immobilon Western (Millipore, Billerica, MA, USA). The same blot was stripped and reblotted with a mouse primary antibody specific to $\beta$-actin (Calbiochem; Merck, Nottingham, UK) to normalise the protein levels. Densitometric analysis of the autoradiographs was performed with a GS-800 calibrated densitometer (Bio-Rad Laboratories, Hercules, CA, USA) and analysed with Quantity One 4.6.2 software (Bio-Rad Laboratories). The measurements were performed at 18 days. Results are presented as densitometry arbitrary units.

Immunohistochemistry Immunohistochemistry was performed in cells grown for 18 days at confluence in 24 well plates containing one circular cover slip of glass $(12 \mathrm{~mm}$ diameter) (Thermo Scientific, Menzel-Gläser; Braunschweig, Germany) inside each well. The details of the method have been reported elsewhere [23].

Cell counting and cytotoxicity Details of cell counting and the methods used to measure cytotoxicity are specified in the ESM.

Human retinas Eight human postmortem eyes were obtained from diabetic donors with non-proliferative diabetic retinopathy (NPDR) in ophthalmological examinations performed during the preceding 2 years. Eight eye cups obtained from non-diabetic donors closely matched by age ( $68 \pm 8$ vs $69 \pm 7$ years) were selected from our eye bank as the control group. The time elapsed from death to eye enucleation was less than $4 \mathrm{~h}$. After enucleation, eyes were snap frozen at $-80^{\circ} \mathrm{C}$ and stored until assayed. Neuroretina and RPE were harvested under the microscopic dissection of isolated eye cups from donors following the protocol described by Sonoda et al. [24].

All ocular tissues were used in accordance with applicable laws and with the Declaration of Helsinki for research involving human tissue. In addition this study was approved by the ethics committee of our hospital.

Statistical analysis Data obtained were evaluated statistically using one-way ANOVA for the comparisons performed 
among more than two groups. Unpaired Student's $t$ test was used to determine the significance of the difference between two different groups. Results were expressed as mean \pm SD. Levels of statistical significance were set at $p<0.05$.

\section{Results}

Effect of high glucose and IL-1 $\beta$ on RPE cell permeability As previously reported by this group [23] permeability was significantly lower in ARPE-19 cells cultured under $25 \mathrm{mmol} / \mathrm{l} \mathrm{D}$-glucose compared with $5.5 \mathrm{mmol} / \mathrm{l} \mathrm{D}$-glucose and this could not be attributed to an osmotic effect (Fig. 1a). The increase in permeability after IL- $1 \beta$ treatment was similar in cells cultured in $5.5 \mathrm{mmol} / 1 \mathrm{D}$-glucose to that in cells cultured in $25 \mathrm{mmol} / \mathrm{l}$ D-glucose (Fig. 1b). Therefore, IL-1 $\beta$ is the main factor accounting for the breakdown of the ARPE-19 cell monolayer.

Fenofibric acid prevents the hyperpermeability induced by $I L-1 \beta$ Treatment of ARPE-19 cells with fenofibric acid significantly reduced the increment of permeability induced

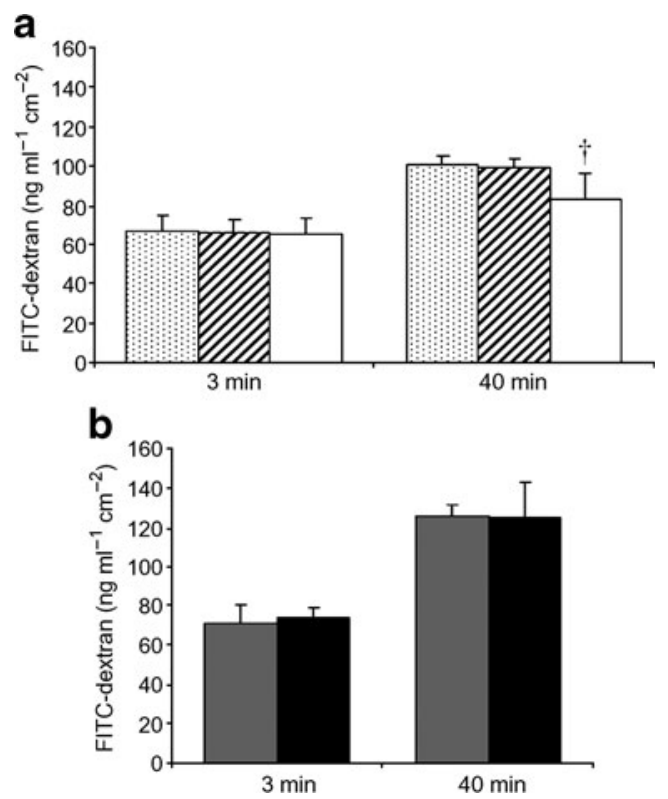

Fig. 1 Results of $40 \mathrm{kDa}$ dextran permeability. The vertical axis is the concentration of dextran and the horizontal axis is the time after the addition of the molecule. a ARPE-19 permeability after treatment with: D-glucose, $5.5 \mathrm{mmol} / 1$ (dotted bars); D-glucose, $5.5 \mathrm{mmol} / \mathrm{l}$, and mannitol, $19.5 \mathrm{mmol} / 1$ (striped bars); and D-glucose, $25 \mathrm{mmol} / 1$ (white bars). Results are expressed as the mean $\pm \mathrm{SD}, n=6 .{ }^{\dagger} p=0.04$ compared with the other conditions at $40 \mathrm{~min}$. Dextran permeability was measured at 3 and $40 \mathrm{~min}$. b ARPE-19 permeability after treatment with: D-glucose, $5.5 \mathrm{mmol} / \mathrm{l}$, and IL- $1 \beta, 10 \mathrm{ng} / \mathrm{ml}$, for $48 \mathrm{~h}$ (dark grey bars); and D-glucose, $25 \mathrm{mmol} / \mathrm{l}$, and IL-1 $\beta, 10 \mathrm{ng} / \mathrm{ml}$, for $48 \mathrm{~h}$ (black bars). Results are expressed as the mean $\pm \mathrm{SD}, n=6$. Dextran permeability was measured at 3 and $40 \mathrm{~min}$ by IL- $1 \beta$. This protective effect on monolayer permeability was more evident in cultures treated with fenofibric acid, $100 \mu \mathrm{mol} / \mathrm{l},(p=0.02$ at $40 \mathrm{~min})$ than in cultures treated with fenofibric acid, $25 \mu \mathrm{mol} / \mathrm{l},(p=0.04$ at $40 \mathrm{~min}$; Fig. 2).

Fenofibric acid prevents the disorganisation of tight junction proteins Immunofluorescence analysis showed a change in cell shape and tight junction disruption in ARPE19 cells cultured under D-glucose, $25 \mathrm{mmol} / \mathrm{l}$, and IL- $1 \beta$. By contrast, treatment with $25 \mu \mathrm{mol} / 1$ fenofibric acid prior to IL-1 $\beta$ supplementation partially preserved monolayer integrity. This protective effect of fenofibric acid was more evident when using a higher concentration $(100 \mu \mathrm{mol} / \mathrm{l})$, which resulted in monolayer integrity being totally preserved (Fig. 3). Claudin-1 immunostaining in IL-1 $\beta$ supplemented cell cultures appeared to be stronger than in the untreated cells, but no significant differences were observed in ZO-1 and occludin staining (Fig. 3).

We did not observe any significant differences for occludin and ZO-1 under different conditions in western blot analyses (data not shown). By contrast, IL-1 $\beta$-treated cultures showed higher levels of claudin-1 than the untreated cells. This increase in claudin-1 after IL-1 $\beta$ supplementation was reduced in a dose-dependent manner when the cells were previously treated with fenofibric acid, 25 or $100 \mu \mathrm{mol} / \mathrm{l}$ (Fig. 4).

Fenofibric acid prevents the activation of AMPK induced by $I L-1 \beta$ AMPK activation was examined in order to study whether this cellular energy sensor participates in the fenofibric-acid-induced effects on epithelial barrier function. We did not find any difference in AMPK activation

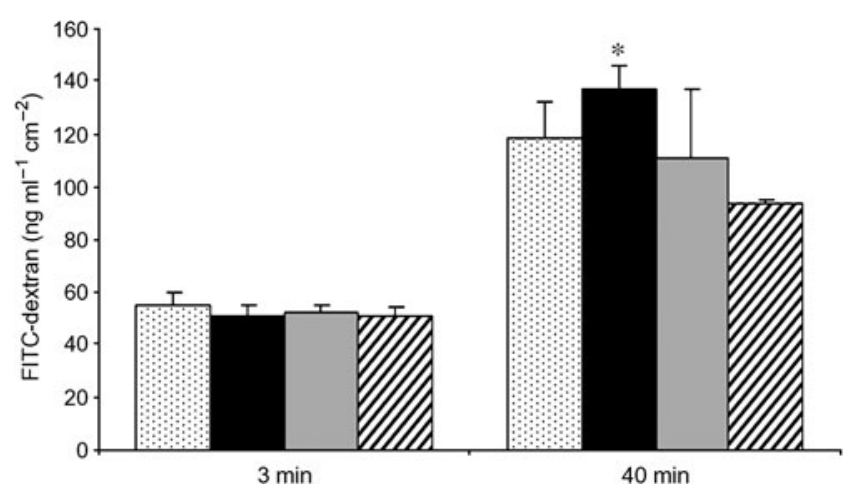

Fig. 2 ARPE-19 permeability after treatment with: D-glucose, $5.5 \mathrm{mmol} / \mathrm{l}$ (dotted bars); D-glucose, $25 \mathrm{mmol} / \mathrm{l}$, and IL-1 $\beta, 10 \mathrm{ng} / \mathrm{ml}$, for $48 \mathrm{~h}$ (black bars); D-glucose, $25 \mathrm{mmol} / \mathrm{l}$, fenofibric acid, $25 \mu \mathrm{mol} / \mathrm{l}$, for $72 \mathrm{~h}$, and IL- $1 \beta, 10 \mathrm{ng} / \mathrm{ml}$, for $48 \mathrm{~h}$ (light grey bars); and D-glucose, $25 \mathrm{mmol} / \mathrm{l}$, fenofibric acid, $100 \mu \mathrm{mol} / 1$, for $72 \mathrm{~h}$ and IL- $1 \beta, 10 \mathrm{ng} / \mathrm{ml}$, for $48 \mathrm{~h}$ (striped bars). Results are expressed as the mean $\pm \mathrm{SD}, n=4$. ANOVA: $p<0.001$; Student's $t$ test: ${ }^{*} p<0.05$ compared with the other conditions at $40 \mathrm{~min}$. Dextran permeability was measured at 3 and $40 \mathrm{~min}$ 


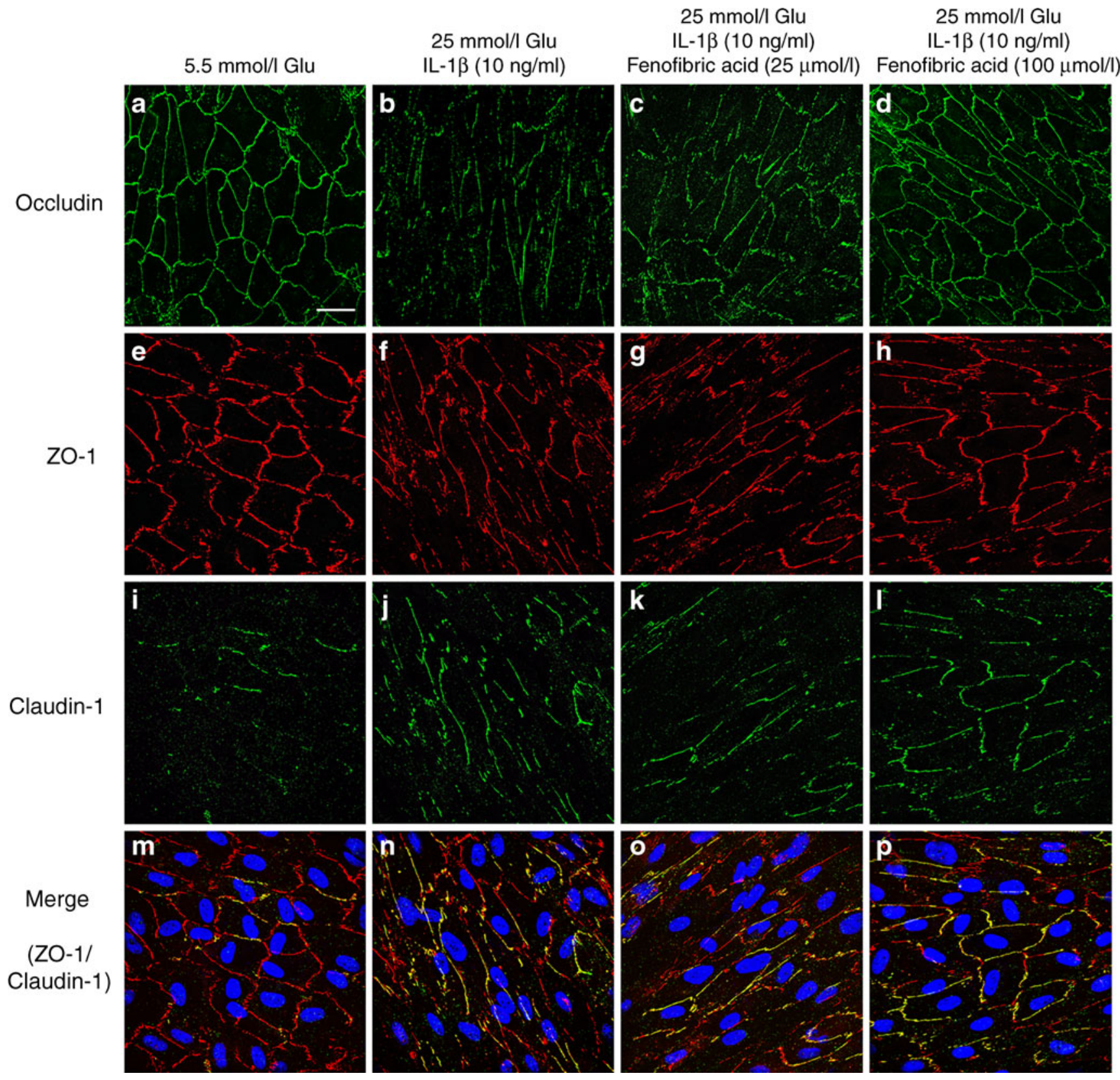

Fig. 3 Immunohistochemistry of ARPE-19 cells showing the disruption of the monolayer induced by IL-1 $\beta$ and the beneficial effects of fenofibric acid, 25 and $100 \mu \mathrm{mol} / \mathrm{l}$, in preventing the disorganisation of tight junction proteins and in maintaining the integrity of the monolayer. (a-d) Occludin and (i-l) claudin-1 staining appears in green and (e-h) ZO-1 staining appears in red. $\mathbf{m}-\mathbf{p}$ Merged images show colocalisation of claudin-1 and ZO-1 (yellow). The nuclei were stained with 4'-6-diamidino-2-phenylindole (DAPI; blue). Scale bar, $20 \mu \mathrm{m}$. Glu, glucose; Claud-1, claudin-1 between 5 and $25 \mathrm{mmol} / \mathrm{l}$ D-glucose. IL-1 $\beta$ treatment caused maximal activation of AMPK in ARPE-19 cells as assessed by phosphorylation of Thr172 of the AMPK catalytic $\alpha$-subunit, which is a well-established marker of AMPK activation. Treatment with $25 \mu \mathrm{mol} / 1$ of fenofibric acid prior to IL-1 $\beta$ supplementation partially prevented IL$1 \beta$-induced activation of AMPK. A higher concentration of fenofibric acid $(100 \mu \mathrm{mol} / \mathrm{l})$, prior to the addition of IL-1 $\beta$, strongly reduced the phosphorylation of AMPK, almost to levels similar to those of the control cells (Fig. 5).

Furthermore, in an additional experiment, cells were treated with $100 \mu \mathrm{mol} / \mathrm{l}$ fenofibric acid for $1 \mathrm{~h}$ before adding IL- $1 \beta, 10 \mathrm{ng} / \mathrm{ml}$. AMPK and AMPK activation were assessed at $0,0.25,1,6$, and $24 \mathrm{~h}$ after incubation. As 


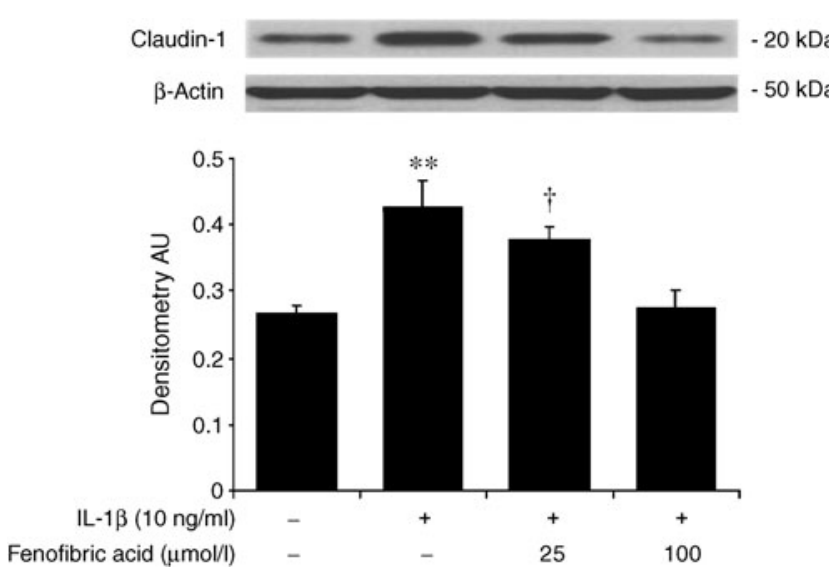

Fig. 4 Western blot showing the increase of claudin-1 after treatment with D-glucose, $25 \mathrm{mmol} / \mathrm{l}$, and IL- $1 \beta, 10 \mathrm{ng} / \mathrm{ml}$, for $48 \mathrm{~h}$ and the preventive effect of fenofibric acid, 25 and $100 \mu \mathrm{mol} / 1$. Protein levels are expressed in arbitrary units after correction for $\beta$-actin. Bars represent the mean $\pm \mathrm{SD}, n=4 .{ }^{* *} p<0.01$ vs control (IL- $1 \beta-$, fenofibric acid-); ${ }^{\dagger} p=0.04$ vs control. AU, arbitrary unit

shown in Fig. 6, the protective effect of fenofibric acid in preventing AMPK phosphorylation induced by IL- $1 \beta$ was lost after $24 \mathrm{~h}$ incubation.

AMPK activation mediates the hyperpermeability induced by $I L-1 \beta$ and it is prevented by fenofibric acid To evaluate the role of AMPK activation in epithelial permeability and tight junction disruption, cells were treated with AICAR, a precursor of AMP that enters cells and causes activation of AMPK. Treatment of ARPE-19 cells with AICAR, 2 mmol/l, caused significant AMPK activation, as assessed by phos-
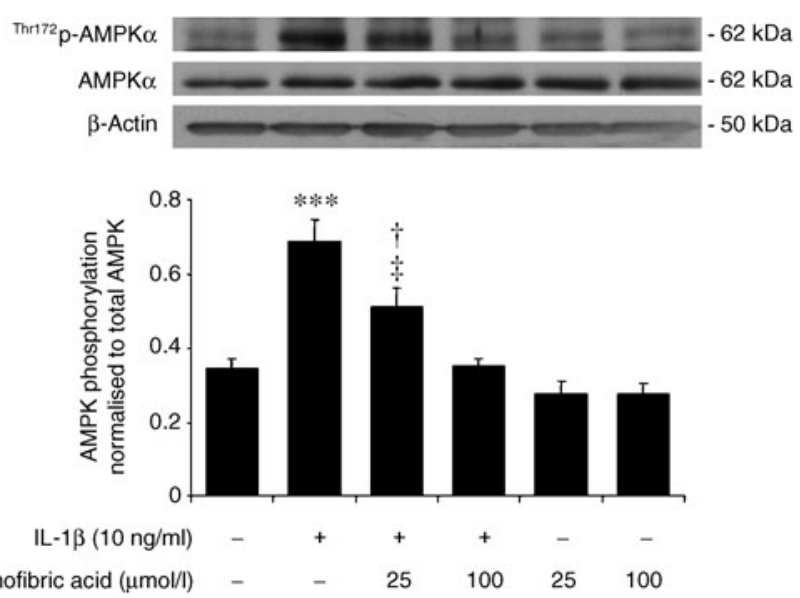

Fig. 5 Western blot showing the increase of AMPK phosphorylation after treatment with D-glucose, $25 \mathrm{mmol} / \mathrm{l}$, and IL- $1 \beta, 10 \mathrm{ng} / \mathrm{ml}$, and the preventive effect of fenofibric acid, 25 and $100 \mu \mathrm{mol} / \mathrm{l}$. AMPK activity is expressed as the ratio of the phosphorylated form of the protein to total protein. Protein levels are expressed in arbitrary units after correction for $\beta$-actin. Bars represent the mean $\pm \mathrm{SD}, n=4 .{ }^{* * *} p<0.001$ vs control (IL- $1 \beta-$, fenofibric acid-); ${ }^{\dagger} p=0.007$ vs control; ${ }^{\star} p=0.003$ vs IL-1 $\beta+$, fenofibric acid-
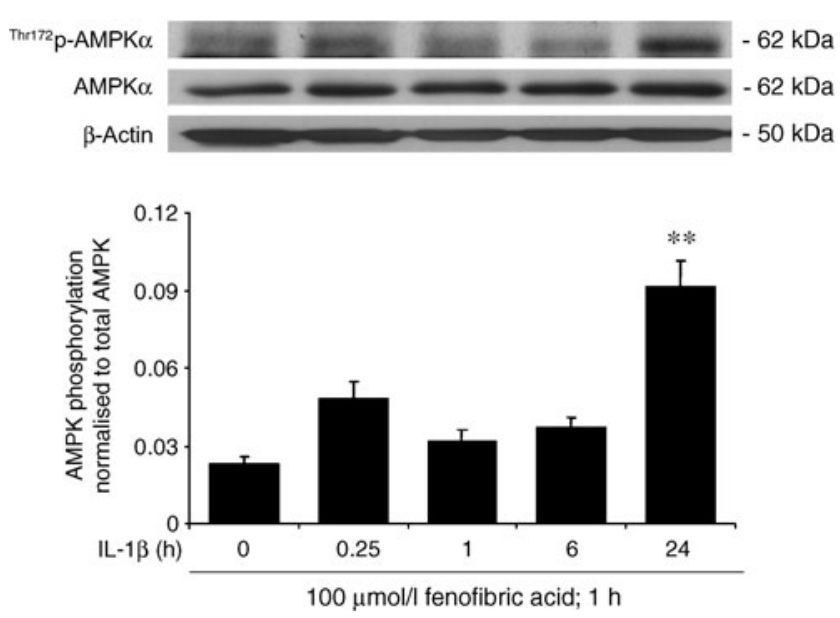

Fig. 6 Western blot of phosphorylated and total AMPK $\alpha$ after treatment with fenofibric acid, $100 \mu \mathrm{mol} / \mathrm{l}$, for $1 \mathrm{~h}$ prior to the addition of IL- $1 \beta$, $10 \mathrm{ng} / \mathrm{ml}$. AMPK activity is expressed as the ratio of the phosphorylated form of the protein to total protein. Protein levels are expressed in arbitrary units after correction for $\beta$-actin. Bars represent the mean $\pm \mathrm{SD}$, $n=4$. ${ }^{* *} p<0.01$ compared with the other conditions

phorylation of Thr172 of the AMPK catalytic $\alpha$-subunit $(p=0.04)$. Treatment with $100 \mu \mathrm{mol} / 1$ fenofibric acid prior to AICAR supplementation prevented AICAR-induced activation of AMPK (Fig. 7a). To determine whether AMPK activation mediates IL- $1 \beta$-induced alterations in RPE permeability we measured FITC-dextran flux in cells treated with IL- $1 \beta$ and in cells treated with AICAR. Under both conditions a significant increase in epithelial permeability was observed compared with cells cultured with $25 \mathrm{mmol} / 1 \mathrm{D}$-glucose $(p=0.01$ and $p=0.02$, respectively; Fig. 7b). Notably, the increase in permeability detected under both conditions was very similar. In addition, treatment with fenofibric acid, $100 \mu \mathrm{mol} / \mathrm{l}$, prior to the addition of AICAR, was able to prevent the increment of permeability induced by AICAR supplementation $(p=0.04$; Fig. 7b). According to these results, immunofluorescence images showed that exposure to fenofibric acid treatment prior to the addition of IL-1 $\beta$ or AICAR prevented the disruption of tight junction proteins and preserved monolayer integrity (Fig. 7c).

In order to confirm whether AMPK $\alpha$ was relevant in accounting for the hyperpermeability induced by IL-1 $\beta$, ARPE-19 cells were transfected with siRNA oligonucleotides targeting $A M P K \alpha 1$ and $A M P K \alpha 2$ isoforms. siRNA to $A M P K \alpha$ was able to significantly reduce mRNA levels of both $A M P K \alpha 1$ and $A M P K \alpha 2$ (by $91.2 \%$ [ $p=0.03$; Fig. 8a] and $60 \%$ [ $p=0.004$; Fig. 8b], respectively). AMPK $\alpha$ protein content was measured by western blot and a $56 \%$ of reduction was observed in cells treated with siRNA to $A M P K \alpha 1$ and $A M P K \alpha 2$ ( $p=0.04$; Fig. $8 \mathrm{c}$ ). To examine the functional effects of these findings we measured the flux of FITC-dextran (40 kDa) across ARPE-19 monolayers. As shown before in 

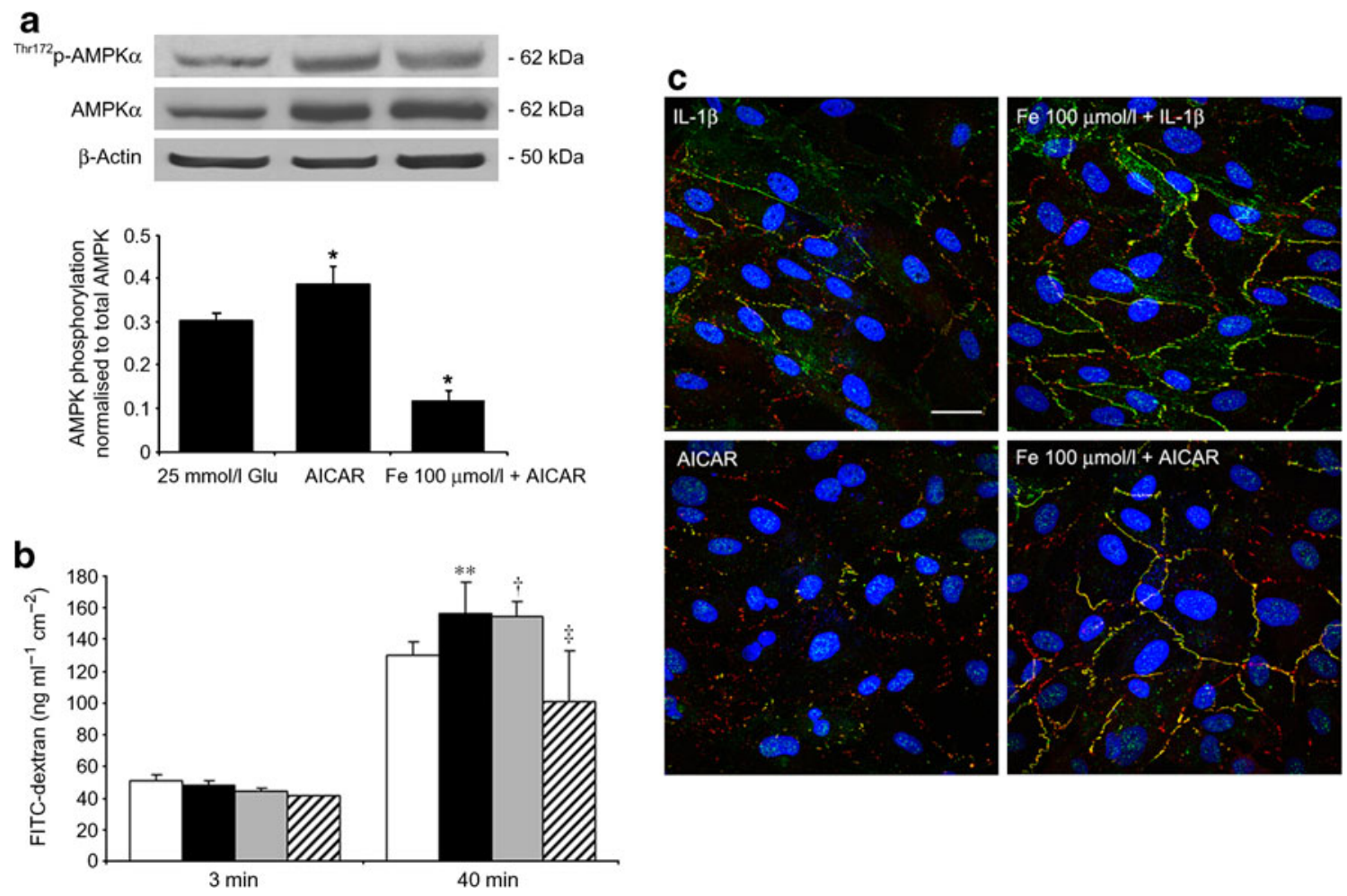

Fig. 7 Results of pharmacological activation of AMPK by AICAR and its effect on human RPE cell permeability. a Western blot of phosphorylated and total AMPK $\alpha$ showing the increase of AMPK phosphorylation induced by AICAR, $2 \mathrm{mmol} / \mathrm{l}$, for $48 \mathrm{~h}$, and the preventive effects of fenofibric acid, $100 \mu \mathrm{mol} / 1$, for $72 \mathrm{~h}$. AMPK activity is expressed as the ratio of the phosphorylated form of the protein to total protein. Protein levels are expressed in arbitrary units after correction for $\beta$-actin. Bars represent the mean $\pm \mathrm{SD}, n=4 .{ }^{*} p<$ 0.05 compared with the other conditions. b Results of $40 \mathrm{kDa}$ dextran permeability. D-Glucose, $25 \mathrm{mmol} / \mathrm{l}$, white bars; D-glucose, $25 \mathrm{mmol} / \mathrm{l}$, and IL- $1 \beta, 10 \mathrm{ng} / \mathrm{ml}$, for $48 \mathrm{~h}$, black bars; D-glucose, $25 \mathrm{mmol} / \mathrm{l}$, and AICAR, $2 \mathrm{mmol} / 1$, for $48 \mathrm{~h}$, grey bars; D-glucose, $25 \mathrm{mmol} / \mathrm{l}$,

fenofibric acid, $100 \mu \mathrm{mol} / \mathrm{l}$, for $72 \mathrm{~h}$ and AICAR, $2 \mathrm{mmol} / \mathrm{l}$, for $48 \mathrm{~h}$, striped bars. Results are expressed as the mean $\pm \mathrm{SD}, n=4$. ${ }^{*} p=$ $0.01,{ }^{\dagger} p=0.02$ and ${ }^{\ddagger} p=0.04$ compared with D-glucose, $25 \mathrm{mmol} / \mathrm{l}$. Dextran permeability was measured at 3 and $40 \mathrm{~min}$. c Immunohistochemistry of ARPE-19 monolayers showing either the disruption of tight junction due to AMPK activation induced by IL- $1 \beta, 10 \mathrm{ng} / \mathrm{ml}$, for $48 \mathrm{~h}$ or by AICAR, $2 \mathrm{mmol} / \mathrm{l}$, for $48 \mathrm{~h}$, and the beneficial effects of previous treatment with fenofibric acid, $100 \mu \mathrm{mol} / 1$, for $72 \mathrm{~h}$ on the maintenance of monolayer integrity. Merged images show colocalisation of claudin-1 and ZO-1 (yellow). Scale bar, $20 \mu \mathrm{m}$. Fe, fenofibric acid; Glu, glucose

Fig. 1, IL-1 $\beta$ produced an increment of permeability that was almost prevented in $A M P K \alpha$-transfected cells $(p=0.03$; Fig. 8d). Finally, the results of the immunohistochemistry showed that the monolayer integrity in $A M P K \alpha$-knockdown cells treated with IL-1 $\beta$ was partially preserved compared with those cells treated with IL-1 $\beta$ (Fig. 8e).

Cell counting and cytotoxicity Results relating to cell counting and cytotoxicity are shown in the ESM.

AMPK activation in human RPE from diabetic and nondiabetic donors AMPK phosphorylation was significantly higher in RPE from diabetic donors with NPDR than in RPE from non-diabetic donors (Fig. 9). In addition, the levels detected in the RPE from diabetic patients were very similar to those obtained in ARPE-19 cells cultured with D-glucose, $25 \mathrm{mmol} / \mathrm{l}$, and IL-1 $\beta$.

\section{Discussion}

It has recently been shown that fenofibrate, a PPAR- $\alpha$ agonist indicated for the treatment of hypertriacylglycerolaemia and mixed dyslipidaemia, reduces the progression of existing DR, thus lessening the need for laser treatment in both DMO and PDR [5]. This beneficial effect is unrelated to quantitative changes in serum lipids but other potential mechanisms, including its potential effect on the BRB, have recently been proposed [8]. In the present study we provide evidence that fenofibrate is able to prevent in a dose-dependent manner the breakdown of the RPE cell monolayer induced by the diabetic milieu, and that this effect is mainly mediated by its ability to lower AMPK activation.

The RPE is a specialised epithelium lying in the interface between the neural retina and the choriocapillaris, where it forms the outer BRB. Tight junctions between neighbouring 


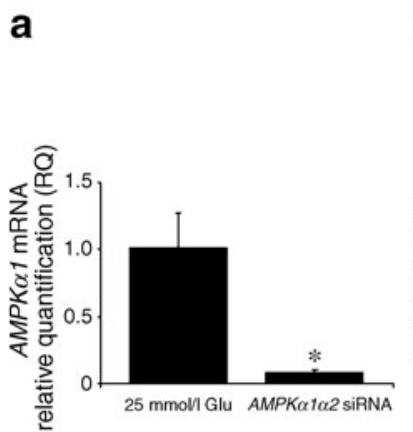

b

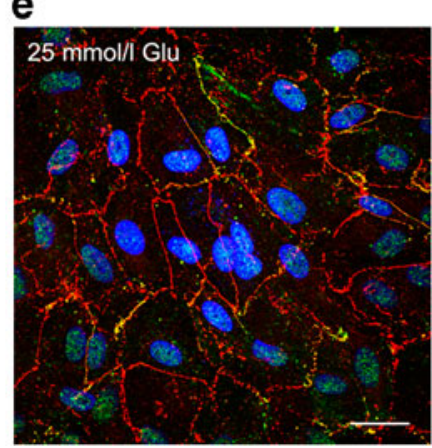

C

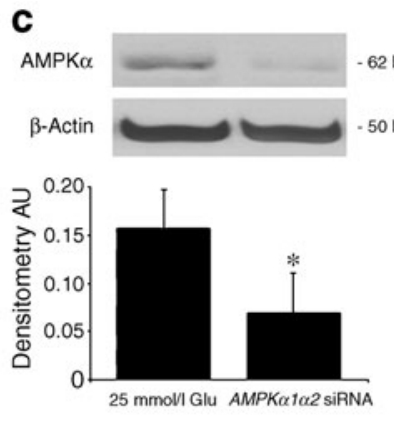

d

$2 \mathrm{kDa}$

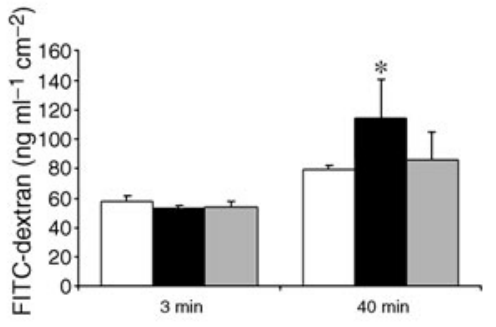

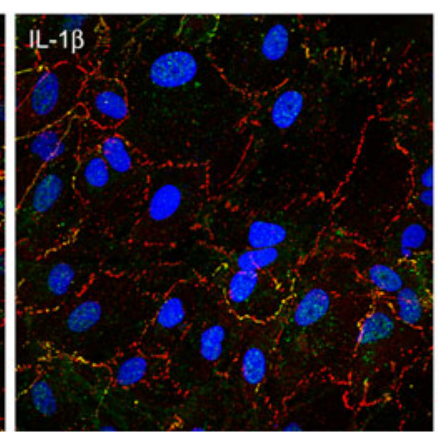

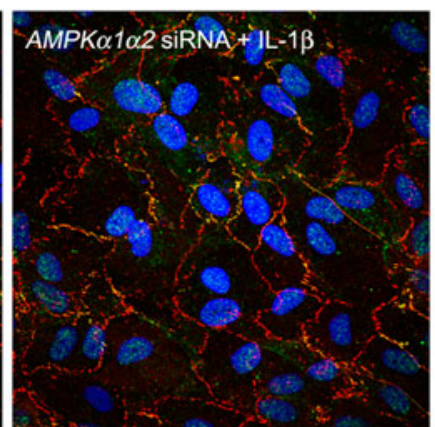

Fig. 8 Results of $A M P K \alpha$ knockdown using siRNA oligonucleotides. a, b Results of real-time PCR. The vertical axis is the relative expression level of (a) the $A M P K \alpha 1$ isoform or (b) the relative expression level of the $A M P K \alpha 2$ isoform. As can be seen both isoforms were significantly silenced by siRNA probes. Gene expression levels were calculated after normalising with $S 18$. Bars represent the mean $\pm \mathrm{SD}, n=3 . * p<0.05$. c Results of western blot analysis showing the effectiveness of siRNA oligonucleotides in reducing the content of AMPK $\alpha$. AMPK $\alpha$ protein levels are expressed in arbitrary units after correction for $\beta$-actin. Bars represent the mean $\pm \mathrm{SD}, n=3$. ${ }^{*} p=0.04$. d Results of $40 \mathrm{kDa}$ dextran permeability showing that
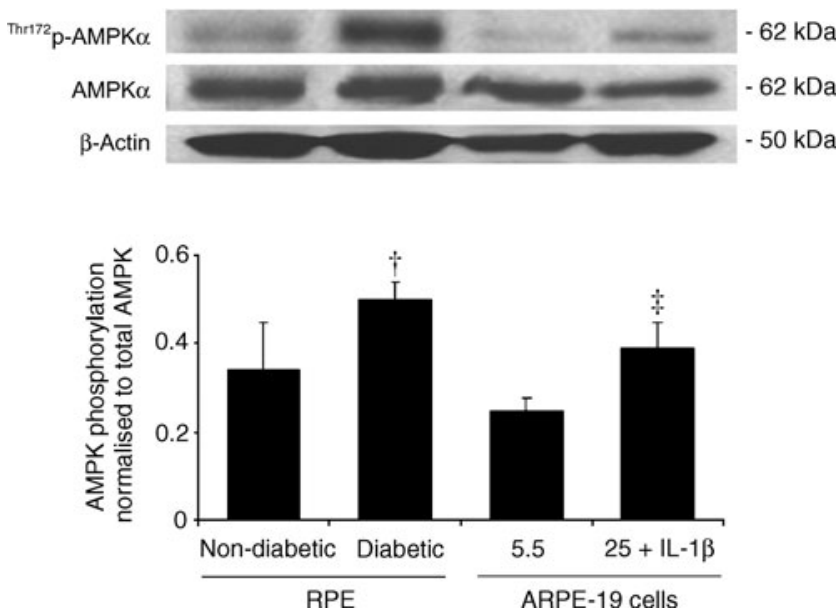

Fig. 9 Western blot showing the increase of AMPK phosphorylation in RPE from diabetic patients ( $p=0.04$ vs non-diabetic patients), and in ARPE-19 cells after treatment with D-glucose, $25 \mathrm{mmol} / \mathrm{l}$, and IL- $1 \beta$, $10 \mathrm{ng} / \mathrm{ml}$, for $48 \mathrm{~h}\left({ }^{\ddagger} p=0.03 \mathrm{vs}\right.$ cells treated with D-glucose, $\left.5.5 \mathrm{mmol} / \mathrm{l}\right)$. AMPK activity is expressed as the ratio of the phosphorylated form of the protein to total protein. Protein levels are expressed in arbitrary units after correction for $\beta$-actin. Bars represent mean $\pm \mathrm{SD}$
AMPK-induced hyperpermeability is prevented by siRNA. D-glucose, $25 \mathrm{mmol} / \mathrm{l}$, white bars; D-glucose, $25 \mathrm{mmol} / \mathrm{l}$, and IL- $1 \beta, 10 \mathrm{ng} / \mathrm{ml}$, for $48 \mathrm{~h}$, black bars; D-glucose, $25 \mathrm{mmol} / \mathrm{l}$, and siRNA targeting $A M P K \alpha \mathrm{l}$ and $A M P K \alpha 2$ and IL- $1 \beta, 10 \mathrm{ng} / \mathrm{ml}$, for $48 \mathrm{~h}$, grey bars. Results are expressed as the mean $\pm \mathrm{SD}, n=4$. ${ }^{*} p<0.05$ compared with the other conditions at $40 \mathrm{~min}$. Dextran permeability was measured at 3 and 40 min. e Immunohistochemistry of ARPE-19 cells treated with IL$1 \beta, 10 \mathrm{ng} / \mathrm{ml}$, for $48 \mathrm{~h}$ and ARPE-19 cells transfected with siRNA targeting the $A M P K \alpha 1$ and $A M P K \alpha 2$ isoforms. Merged images show colocalisation of claudin-1 and ZO-1 (yellow). Scale bar, $20 \mu \mathrm{m}$. AU, arbitrary unit; Glu, glucose

RPE cells and neighbouring endothelial cells are essential in the strict control of fluids and solutes that cross the BRB, as well as in preventing the entrance of toxic molecules and plasma components into the retina. Apart from this sealing function, RPE cells have other essential functions for the integrity of the retina [25]. Most of the research on the pathophysiology of diabetic retinopathy has been focused on the impairment of the neuroretina and the breakdown of the inner BRB. By contrast, the effects of diabetes on the RPE have received less attention.

Pro-inflammatory cytokines such as IL-1 $\beta$ play a crucial role in the pathogenesis of both PDR and DMO [19-22]. Apart from its intrinsic deleterious effect, IL- $1 \beta$ has been shown to stimulate several pro-inflammatory cytokines such as IL-6, IL-8 and monocyte chemotactic protein 1 (MCP-1) [26, 27], which, in turn, have also been involved in both PDR and DMO [28-30]. It is well known that IL$1 \beta$ participates in the breakdown of the inner BRB, which is constituted by retinal capillaries [31-33]. In addition, it has been also demonstrated that IL-1 $\beta$ induces the disruption of the barrier function of RPE cells, thus 
resulting in an increased permeability [17]. Although this effect was associated with the aberrant production of tight junctions (downregulation of occludin and upregulation of claudin-1), the intracellular signalling pathways that mediate these effects remain to be elucidated. In the present study we have confirmed that exposure to IL- $1 \beta$ is a good method for inducing the breakdown of the RPE cells and that this is associated with an upregulation of claudin-1. However, we have not found any differences in the levels of occludin and ZO-1. The upregulation of claudin-1 induced by IL-1 $\beta$ was prevented by fenofibric acid in a dose-dependent manner. It could be expected that claudin-1 enhancement should be associated with a decrease rather than an increase in permeability, but this was not the case. In addition, we have recently shown that the upregulation of claudin-1 in ARPE-19 cells cultured under high glucose conditions (D-glucose, $25 \mathrm{mmol} / \mathrm{l}$ ) was not related to changes in permeability [23]. Taken together, these findings suggest that an ordered distribution, rather than a crude assortment, of tight junction proteins is essential for the efficient functioning of RPE barrier. Fenofibric acid was able to reduce (at $25 \mu \mathrm{mol} / \mathrm{l}$ ) or prevent (at $100 \mu \mathrm{mol} / \mathrm{l}$ ) the disorganisation of tight junction proteins and it was associated with the preservation of the sealing function of RPE cells, which was also dose dependent. It is reasonable to deduce that the effect of fenofibric acid in preventing the breakdown of the RPE monolayer is mediated by its effect in maintaining the structural disposition of tight junction proteins. However, the complexity of the tight junction complex is just beginning to be understood in epithelial model systems and the relative contribution of the various functional proteins to BRB properties and the changes in permeability in disease states will be critical areas for future study. Therefore, apart from preventing the abnormal distribution of the tight junction proteins herein determined, fenofibric acid might also modulate other tight junction proteins, as well as other systems involved in RPE permeability.

AMPK is an evolutionarily conserved energy sensor in eukaryotic cells. It is activated by allosteric binding of AMP and through phosphorylation of its Thr172 residue in the activation loop by upstream kinases [34-36]. AMPK functions as a metabolic switch, thereby coordinating the cellular enzymes involved in carbohydrate and fat metabolism to enable ATP conservation and synthesis. When AMPK is activated by AMPK kinase, and a conformational change is induced by combining with AMP, the AMP/ATP ratio is decreased because ATP-consuming pathways are switched off and ATP-generating pathways are switched on [34-36]. AMPK can be triggered by an increased cellular AMP/ATP ratio under energy stress, such as hypoxia, ischaemia, glucose deprivation and oxidative stress. AMPK can also be activated in response to physiological stimuli such as exercise and contraction in skeletal muscle, and to the peptide hormones leptin and adiponectin [34-36]. The induction of AMPK activation by IL-1 $\beta$ detected in the present study, as well as the effect of fenofibric acid in preventing this activation, has not been previously reported. In addition, we have found that AMPK activation induced by AICAR leads to an increase of permeability due to the breakdown of the ARPE-19 cell monolayer similar to that provoked by IL-1 $\beta$, and it is also prevented by fenofibric acid. Furthermore, the hyperpermeability induced by IL-1 $\beta$ can be prevented by silencing AMPK $\alpha$. These findings strongly suggest: (1) the disruption of RPE cells provoked by IL- $1 \beta$ is mediated by AMPK activation rather than as a direct effect of IL-1 $\beta$ on tight junction protein production; and (2) the effect of fenofibric acid in preventing the disruption of human RPE cells is mediated by its ability to lower AMPK activation induced by IL- $1 \beta$ or, in other words, fenofibric acid is able to anchor tight junction proteins and prevent their disorganisation by downregulating AMPK activation. Notably, we found that AMPK activation in human RPE from diabetic donors was significantly higher than in RPE from non-diabetic donors, and very similar to those obtained in ARPE-19 cells cultured under D-glucose, $25 \mathrm{mmol} / \mathrm{l}$, and IL-1 $\beta$. These findings suggest that our results obtained in vitro could be transferred to the events that are taking place in the human diabetic retina, and point towards suppression of AMPK activation as a mechanism by which fenofibrate might prevent or arrest DMO.

AMPK activation can exert different effects in maintaining tight junction integrity depending on the cell type. In this regard, whereas AMPK activation has been recently involved in the disruption of the intestinal epithelial barrier induced by interferon- $\gamma$ [37], it can also facilitate the assembly of tight junctions in certain epithelial cells such as Madin-Darby canine kidney (MDCK; a canine line of kidney epithelial cells) $[38,39]$. Therefore, the effects of fenofibric acid in increasing the sealing function of RPE cells by means of lowering AMPK activation cannot be extrapolated to other cell types.

Finally, it should be stressed that we found that IL- $1 \beta$ rather than high glucose level was the main factor accounting for the breakdown of the ARPE-19 cell monolayer. In addition, we provide evidence that fenofibric acid exerts its dose-dependent protective effects by blocking IL- $1 \beta$-induced AMPK activation independently of glucose levels. These findings support the concept that inflammation, and in particular IL- $1 \beta$, plays a crucial role in the pathogenesis of DMO. In this regard it is worth noting that Busik et al. [40] have reported that diabetesrelated endothelial injury in the retina may be due primarily to glucose-induced cytokine release by neighbouring cells rather than the direct effect of high glucose on endothelial cells. However, we have only explored the effect of 
fenofibric acid in RPE cells (outer BRB) and, as a consequence, further studies are needed to elucidate the effect of fenofibric acid on the sealing function of retinal endothelial cells (inner BRB).

In summary, treatment of ARPE-19 cells with fenofibric acid significantly reduced the increment of permeability and the breakdown of the ARPE cell monolayer induced by IL-1 $\beta$ in a dose-dependent manner. This effect was mainly mediated by its ability to lower AMPK activation induced by IL- $1 \beta$. These findings contribute significantly to increasing our knowledge about why fenofibrate has beneficial effects on DMO development.

Acknowledgements This study was supported by grants from Ministerio de Ciencia e Innovación (SAF2009-07408) and CIBERDEM. CIBERDEM is an initiative of the Instituto de Salud Carlos III. We acknowledge the assistance of Abbott Laboratories in providing fenofibric acid.

Duality of interest R. Simó received grant support from Novo Nordisk and Abbott Laboratories, and advisory fees from Novo Nordisk, Elli Lilly, Pfizer and Novartis, as well as travel and accommodation expenses from all these companies. The remaining authors declare that there is no duality of interest associated with this manuscript.

\section{References}

1. Congdom N, Friedman DS, Lietman T (2006) Important causes of visual impairment in the world today. JAMA 290:2057-2060

2. Lightman S, Towler HM (2003) Diabetic retinopathy. Clin Cornerstone 5:12-21

3. Simó R, Carrasco E, García-Ramírez M, Hernández C (2006) Angiogenic and antiangiogenic factors in proliferative diabetic retinopathy. Curr Diabet Rev 2:71-98

4. Joussen A, Smyth N, Niessen C (2007) Pathophysiology of diabetic macular edema. Dev Ophthalmol 39:1-12

5. Keech A, Mitchell P, Summanen P et al (2007) Effect of fenofibrate on the need for laser treatment for diabetic retinopathy (FIELD study): a randomised controlled trial. Lancet 370:1687-1697

6. The ACCORD Study Group, ACCORD Eye Study Group (2010) Effects of medical therapies on retinopathy progression in type 2 diabetes. N Engl J Med 363:233-244

7. Simó R, Hernández C (2007) Fenofibrate for diabetic retinopathy. Lancet 370:1667-1668

8. Simó R, Hernández C (2009) Advances in the medical treatment of diabetic retinopathy. Diab Care 32:1556-1562

9. Schaefer MB, Pose A, Ott J et al (2008) Peroxisome proliferatoractivated receptor-alpha reduces inflammation and vascular leakage in a murine model of acute lung injury. Eur Respir J 32:1344-1353

10. Strauss $O$ (2005) The pigment epithelium in visual function. Physiol Rev 85:845-881

11. Erickson KK, Sundstrom JM, Antonetti DA (2007) Vascular permeability in ocular disease and the role of tight junctions. Angiogenesis 10:103-117

12. Kern TS (2007) Contributions of inflammatory processes to the development of the early stages of diabetic retinopathy. Exp Diabetes Res 2007:95103
13. Gardner TW, Antonetti DA (2008) Novel potential mechanisms for diabetic macular edema: leveraging new investigational approaches. Curr Diab Rep 8:263-269

14. Chang CW, Ye L, Defoe DM, Caldwell RB (1997) Serum inhibits tight junction formation in cultured pigment epithelial cells. Invest Ophthalmol Vis Sci 38:1082-1093

15. Zech JC, Pouverau I, Cotinet A, Goureau O, Le Varlet B, deKozak Y (1998) Effect of cytokines and nitric oxide on tight junctions in cultured rat retinal pigment epithelium. Invest Ophthalmol Vis Sci 39:1600-1608

16. Jin M, Barron E, He S, Ryan SJ, Hinton DR (2002) Regulation of RPE intercellular junction integrity and function by hepatocyte growth factor. Invest Ophthalmol Vis Sci 43:2782-2790

17. Abe T, Sugano E, Saigo Y, Tamai M (2003) Interleukin-1 $\beta$ and barrier function of retinal pigment epithelial cells (ARPE-19): aberrant expression of junctional complex molecules. Invest Ophthalmol Vis Sci 44:4097-4104

18. Miyamoto N, de Kozak Y, Jeanny JC et al (2007) Placental growth factor-1 and epithelial haemato-retinal barrier breakdown: potential implications in the pathogenesis of diabetic retinopathy. Diabetologia 50:461-470

19. Kowluru RA, Odenbach S (2004) Role of interleukin-1beta in the pathogenesis of diabetic retinopathy. Br J Ophthalmol 88:1343-1347

20. Gerhardinger C, Costa MB, Coulombe MC, Toth I, Hoehn T, Grosu P (2005) Expression of acute-phase response proteins in retinal Müller cells in diabetes. Invest Ophthalmol Vis Sci 46:349-357

21. Demircan N, Safran BG, Soylu M, Ozcan AA, Sizmaz S (2006) Determination of vitreous interleukin-1 (IL-1) and tumour necrosis factor (TNF) levels in proliferative diabetic retinopathy. Eye 20:1366-1369

22. Vincent JA, Mohr S (2007) Inhibition of caspase-1/interleukin-1 beta signaling prevents degeneration of retinal capillaries in diabetes and galactosemia. Diabetes 56:224-230

23. Villarroel M, Garcia-Ramírez M, Corraliza L, Hernández C, Simó R (2009) Effects of high glucose concentration on the barrier function and the expression of tight junction proteins in human retinal pigment epithelial cells. Exp Eye Res 89:913-920

24. Sonoda S, Spee C, Barron E, Ryan SJ, Kannan R, Hinton DR (2009) A protocol for the culture and differentiation of highly polarized human retinal pigment epithelial cells. Nat Protoc 4:662-673

25. Simó R, Villarroel M, Corraliza L, Hernández C, Garcia-Ramírez M (2010) The retinal pigment epithelium: something more than a constituent of the blood-retinal barrier-implications for the pathogenesis of diabetic retinopathy. J Biomed Biotechnol 2010:190724

26. Holtkamp GM, van Rossem M, de Vos AF, Willekens B, Peek R, Kjilstra A (1998) Polarized secretion of IL-6 and IL-8 by human retinal pigment epithelial cells. Clin Exp Immunol 112:34-43

27. Holtkamp GM, de Vos AF, Peek R, Kjilstra A (1999) Analysis of the secretion pattern of monocyte chemotactic protein-1 (MCP-1) and transforming growth factor-beta 2 (TGF-beta 2) by human retinal pigment epithelial cells. Clin Exp Immunol 118:35-40

28. Funatsu H, Noma H, Mimura T, Eguchi S, Hori S (2009) Association of vitreous inflammatory factors with diabetic macular edema. Ophthalmology 116:73-79

29. Yoshimura T, Sonoda KH, Sugahara M et al (2009) Comprehensive analysis of inflammatory immune mediators in vitreoretinal diseases. PLoS ONE 4:e8158

30. Hernández C, Segura RM, Fonollosa A, Carrasco E, Francisco G, Simó R (2005) Interleukin-8, monocyte chemoattractant protein-1 and IL-10 in the vitreous fluid of patients with proliferative diabetic retinopathy. Diabet Med 22:719-722 
31. Martiney JA, Lieak M, Berman JW, Arezzo JC, Brosnan CF (1990) Pathophysiologic effect of interleukin-1 $\beta$ in the rabbit retina. Am J Pathol 137:1411-1423

32. Luna JD, Chan CC, Derevjanik NL et al (1997) Blood-retinal barrier (BRB) breakdown in experimental autoimmune uveoretinitis: comparison with vascular endothelial growth factor, tumor necrosis factor alpha, and interleukin-1beta-mediated breakdown. J Neurosci Res 49:268-280

33. Bamforth SD, Lightman SL, Greenwood J (1997) Interleukin-1 beta-induced disruption of the retinal vascular barrier of the central nervous system is mediated through leukocyte recruitment and histamine. Am J Pathol 150:329-340

34. Luo Z, Saha AK, Xiang X, Ruderman NB (2005) AMPK, the metabolic syndrome and cancer. Trends Pharmacol Sci 26:69-76

35. Carling D (2004) The AMP-activated protein kinase cascade-a unifying system for energy control. Trends Biochem Sci 29:18-24
36. Kahn BB, Alquier T, Carling D, Hardie DG (2005) AMPactivated protein kinase: ancient energy gauge provides clues to modern understanding of metabolism. Cell Metab 1:15-25

37. Scharl M, Paul G, Barrett KE, McCole DF (2009) AMP-activated protein kinase mediates the interferon-gamma-induced decrease in intestinal epithelial barrier function. J Biol Chem 284:2795227963

38. Zhang L, Li J, Young LH, Caplan MJ (2006) AMP-activated protein kinase regulates the assembly of epithelial tight junctions. Proc Natl Acad Sci USA 103:17272-17277

39. Zheng B, Cantley LC (2007) Regulation of epithelial tight junction assembly and disassembly by AMP-activated protein kinase. Proc Natl Acad Sci USA 104:819-822

40. Busik JV, Mohr S, Grant MB (2008) Hyperglycemia-induced reactive oxygen species toxicity to endothelial cells is dependent on paracrine mediators. Diabetes 57:1952-1965 